
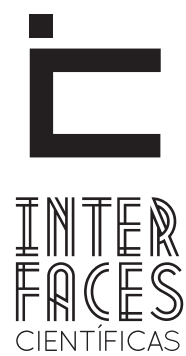

EDUCAÇ̃̃O

ISSN IMPRESSO 2316-333X

ISSN ELETRÔNICO 2316-3828

Dossiê

\title{
A CONTRIBUIÇÃO DO ORATÓRIO FESTIVO SÃO JOÃO BOSCO NA FORMAÇÃO DE MENINAS CIVILLZADAS
}

Nadja Santos Bonifácio ${ }^{1}$

\section{RESUMO}

Este artigo faz parte de dissertação de mestrado e apresenta resultados sobre a formação de meninas pobres e órfãs que viveram/estudaram no Oratório Festivo “São João Bosco". 0 artigo busca apresentar a cultura escolar por meio das práticas educativas promovidas e desenvolvidas pela instituição em diversos momentos do dia. Para produzir esse artigo utilizamos documentos orais e escritos. E como aporte teórico- -metodológico os pressupostos da História Cultural e os conceitos de apropriação e representação de Roger Chartier, Habitus de Pierre Bourdieu Processo Civilizador de Norbert Elias.

\section{PALAVRAS-CHAVE}

Internato. Infância. Sergipe. Século XX. 


\section{ABSTRACT}

This article is part of dissertation and presents results on the formation of poor girls and orphans who lived/ studied in the Oratorio Festivo São João Bosco. The article seeks to present the school culture through educational activities promoted and developed by the institution at various times of the day to produce this article we use oral and written documents. And as contribution methodology-theoretical assumptions

\section{RÉSUMEN}

Este artículo es parte de la tesis doctoral y presenta los resultados sobre la formación de las niñas pobres y huérfanos que vivían/estudiaron en el Oratorio Festivo São João Bosco. El artículo pretende presentar la cultura escolar a través de prácticas educativas promovido y desarrollado por la institución en distintos momentos del dia. Para producir este artículo utilizamos documentos escritos y orales. Y como contri- of Cultural history and the concepts of ownership and representation of Roger Chartier, Pierre Bourdieu of Habitus, Civilizing Process of Norbert Elias.

\section{KEYWORDS}

Boarding school. Childhood. Sergipe. The 20th Century.

bución supuestos teórico-metodológico de la historia Cultural y los conceptos de apropriación y representación de Roger Chartier, Habitus de Bourdieu, Processo civilizador de Norbert Elias.

\section{PALABRAS CLAVE}

Internado. Infancia. Sergipe. El siglo XX. 


\section{INTRODUÇã̃o}

Este artigo faz parte de dissertação de mestrado e apresenta resultados sobre a formação de meninas pobres e órfãs que viveram/estudaram no Oratório Festivo “São João Bosco".

No curso do século XIX e início do XX, os discursos dos republicanos assumiram diversas formas de linguagem ${ }^{2}$, visando construir uma nação civilizada e, por conseguinte produziu uma representação estigmatizada do pobre. A desintegração familiar, os hábitos rudes, os vícios (principalmente álcool e fumo), a forma de se vestirem - andar descalço e com roupas sujas foram alguns dos aspectos que auxiliaram a sintetizar uma imagem estigmatizada do pobre na sociedade. 0 pobre, ás vezes, avaliado fraco, física e moralmente, tornou-se alvo dos homens da ciência ${ }^{3}$, que "auto-representa[ram]-se como porta-vozes da razão, do progresso e da modernidade" (ROCHA, 2003, p. 32), entendiam a deficiência física e moral como consequência da "falta de cultura, de educação e de civilização”. Desse modo, o pobre tornava-se incapaz de criar e educar seus filhos. (RAGO, 1997, p. 113)

Sendo as famílias dessas crianças consideradas incapacitadas, despreparadas (ou inexistentes) para bem criá-las, os estabelecimentos de internamentos seriam ideais para tirar as crianças dos perigos da rua, do botequim, da malandragem, da vadiagem, etc. Retirada da família e da sociedade, para bem construir sua família, dentro do amor e do preparo para o trabalho. Pelo menos essas eram as expectativas utópicas dos teóricos filantropos. Com a maioridade, a criança sairia desse microcosmo estruturado e profilático e seria devolvida "apta” para viver em sociedade. (MARCíLIO, 2006, p. 207).

Dessa forma tornava-se urgente - naquele mo-

2. Entende-se a apropriação como percepção de sentido na qual o receptor interage com "formas" de linguagem "(escritas, visuais, sonoras)" possibilitando-Ihe "inventar, produzir seus significados", suas representações das práticas de modo "singular", a depender de suas leituras, "em cada circunstância". CHARTIER, 2002, p. 68; CHARTIER, 1999, p. 77 e 91.

3. Parcela formada por médicos-higienistas, sanitaristas, eugenistas, juristas, engenheiros, educadores. MARCíLIO, 2006, p. 194. mento civilizador - combater a falta de conhecimento da população concernente à educação moral, física e higiênica, tendo em vista, instruir a população contra as doenças causadas pela falta de higiene.

Kuhlmann Jr. (2002, p. 464) ressaltou que a partir do século XIX, o discurso de proteção à infância impulsionou em todo o mundo ocidental, a criação de uma série de associações e instituições para cuidar da criança, sob diferentes aspectos da sua saúde e sobrevivência.

Para os reformadores a escola representava o espaço ideal para modificar o cenário de atraso e ignorância do povo brasileiro. Nela aprender-se-ia a delimitar o tempo e o espaço, a amoldar os sentidos, acentuar as diferenças, pois, "a criança simbolizava a esperança - o futuro da nação" (RIZZINI, 2008, p. 25).

Os debates realizados em Conferências e Congres$\operatorname{sos}^{4}$ voltados para a educação e para infância impeliram a construção de instituições modelares para a formação da criança, bem como, fatores para sua escolarização desde cedo. "A representação no caso da criança pobre [era de que] se fosse educada devidamente ou, se necessário, retirada de seu meio (tido enfermiço) e reeducada, ela se tornaria útil à sociedade" (RIZZINI, 2008, p. 25). Através da implantação de internatos, os quais ofereciam formação profissional para meninos (RIZZINI, 2009, p. 22) e a educação doméstica para as meninas.

Em Sergipe, no início do século XX surgiram instituições governamentais e religiosas para a infância pobre com o fim de produzir um novo homem, tal como: a Escola de Aprendizes e Artífices em 1910, preparando "os filhos dos pobres para atenderem ao mercado urbano, que necessitava de profissionais marceneiros, sapateiros e alfaiates" (PATRícIO, 2003, p. 3-5); a Cidade de Menores "Getúlio Vargas" que mantinha menores abandonados criminosos e me-

4. Sobre o assunto conferir: KUHLMANN JR., 2002, p. 459-495. 
nores de "famílias muito pobres" que procuravam a instituição por não ter condições de criá-los (BISPO, 2003, p. 58); a Escola Agrotécnica de São Cristóvão, (NASCIMENTO, 2004; NERY, 2006; CONCEIÇÃO, 2007) que proporcionou instrução aos jovens da área rural e pobre de Sergipe, e do mesmo modo contemplou educação a jovens pobres de outros Estados.

Dentre as instituições de cunho católico destacam-se o Oratório Festivo São João Bosco localizado em Aracaju (BONIFÁCIO, 2011), mantido pela Congregação das Ministras dos Enfermos de São Camilo; o Orfanato São Cristóvão, localizado no município de São Cristóvão mantido pela Congregação Religiosa "Irmãs Missionárias da Imaculada Conceição da Mãe de Deus”, ambos para acolhimento de menores órfãs/ pobres; a Escola Nossa Senhora do Bom Conselho criada em 1932 no Colégio Nossa Senhora de Lourdes em Aracaju, oferecia às filhas de operários e empregadas domésticas "curso primário" (COSTA, 2003, p. 60-61); a Escola de Santo Antônio com ensino gratuito estabelecida no Colégio Nossa Senhora das Graças no município de Propriá, em 1916. (MELO, 2007, p. 66-67); e o Lar Nossa Senhora das Graças fundado pela Congregação Santa Terezinha para atender os filhos dos pobres em Boquim (RODRIGUES, 2008, p. 68). Essas Escolas para pobres localizavam-se anexas a Colégios de meninas ou de meninos da elite do Estado, ou anexas a Igrejas ou conventos.

\begin{abstract}
Diferenças, distinções, desigualdades Desde seus inícios a instituição escolar exerceu uma ação distintiva. Ela se incumbiu de separar os sujeitos - tomando aqueles que nela entraram distintos dos outros, os que a ela não tinham acesso. Ela dividiu também, internamente, os que lá estavam, através de múltiplos mecanismos de classificação, ordenamento, hierarquização. A escola que nos foi legada pela sociedade ocidental moderna começou por separar adultos de crianças, católicos de protestantes. Ela também se fez diferente para os ricos e para os pobres e ela imediatamente separou os meninos das meninas. (LOURO, 1997, p. 57)
\end{abstract}

A Igreja foi uma das várias entidades que procurou doutrinar crianças e jovens dessa forma. Para isso, manteve uma rede de instituições e colaboradores que "seguindo o exemplo de outros setores [realizaram] congressos católicos visando organizar e homogeneizar o clero e os leigos militantes para a implementação de novas políticas assistenciais" (KUHLMANN, Jr. 1998, p. 94). Dessa maneira, procuravam distinguir sua presença e assegurar seu poder no campo, formando bons cidadãos (homens cristãos e mulheres cristãs), conscientizados de seu lugar e função na sociedade.

\section{A EDUCAÇÃO NO INTERNATO DO ORATÓRIO FESTIVO SÃO JOÃO BOSCO}

O Oratório Festivo São João Bosco fundado em 1914, na cidade de Aracaju, Sergipe, por Genésia Fontes benemérita e cooperadora, tinha por finalidade acolher, instruir e educar meninas pobres e órfãs. Desde 1952 até os dias de hoje a instituição funciona sob a direção das Ministras dos Enfermos de São Camilo (Irmãs Camilianas). Mas até a primeira metade do século XX, adotou como modelo de ensino dos Salesianos, o Sistema Preventivo de Dom Bosco.

Dom Bosco formulou um Sistema Preventivo calcado em três pilares: Religião, Razão e Amorevolezza, que significa amabilidade, afabilidade, afeto, carinho. Mas não um "amor vago, açucarado, cheio de melindres e ciúmes"; o sentido da Amorevolezza, "exigia solicitude inteligente e racionalidade” (SANTOS, 2000, p. 165). A Amorevolezza, diz Scaramussa:

Exprime adequadamente o modo de agir de D. Bosco
educador: apresentando-se como pai e declaradamen-
te como amigo dos seus alunos, participando com in-
teresse de suas diversões, em comunhão de vida com
eles, com a função e a efetiva capacidade de guiá-los e
ajudá-los a adquirir os valores religiosos, éticos, cultu-
rais ou profissionais, ele consegue, ao mesmo tempo,
a confiança e o respeito, fundamentos da interação
educativa. (SCARAMUSSA, 1977, p. 64).

Dessa forma, para Dom Bosco a presença do educador junto ao educando era o fator fundante, con- 
tanto que, tivesse o espírito da alegria, da vivacidade. Conforme o sacerdote, seria num ambiente de familiaridade, livre e espontâneo, por intermédio das brincadeiras e das conversas, que o mestre poderia conquistar a confiança do jovem, visando desenvolver com facilidade os ensinamentos da religião e da razão, que para Dom Bosco estava atrelado ao "conteúdo humanístico". E para isso, o educador teria que demonstrar a seus alunos espontaneidade, pois a Amorevolezza era também um mecanismo de correção através da palavra ao ouvido, de avisos particulares e públicos, da prática da "Boa-Noite”, de bilhetinhos e outros.

Porém, essa postura espontânea e compreensiva dos mestres fez parte do processo civilizador. Norbert Elias (1994) considerou como uma necessidade de mostrar o controle de si entre os demais, visto que:

Torna-se imediatamente claro que esta maneira polida, extremamente gentil e relativamente atenciosa de corrigir alguém, sobretudo quando exercida por um superior, é um meio muito mais forte de controle social, muito mais eficaz para inculcar hábitos duradouros do que o insulto, a zombaria ou ameaça de violência física. (ELIAS, 1994, p. 93).

Quanto à religião, Dom Bosco concebia que somente a instrução catequética direcionava a maturidade do jovem na verdadeira religião e na moral cristã. Em seu ponto de vista, a educação à piedade exigia convicção pessoal de inteligência e de fé; exigia racionalidade e discrição; visava à adesão do coração. Dessa forma, a evangelização dos alunos não se daria apenas nas salas de aula, mas, sobretudo em suas práticas religiosas diárias, auxiliando nos rituais religiosos, nas celebrações eucarísticas, nas funções litúrgicas, na participação das festas religiosas e escolares, dos exercícios espirituais, no exercício mensal da boa morte e outros. (SCARAMUSSA, 1977, p. 78-79).

Para o desdobramento do Sistema Preventivo de Dom Bosco outros instrumentos foram essenciais: 0 uso do pátio, a Igreja, as brincadeiras e jogos, o espor- te, o teatro (preferindo os temas cômicos aos dramáticos), a música e o canto, ou seja, elementos que promoviam a alegria e a ludicidade da criança e do jovem.

O Oratório Festivo “São João Bosco" oferecia modalidades de ensino formal e informal. A modalidade informal equivalia ao Oratório Festivo ou centro de recreação, mantidos pela instituição. Atendiam em média 250 oratorianas todos os domingos, feriados, dias santificados e no carnaval. (Relatório, 1932-1950). Esses dias representavam os dias de folga das escolas públicas, de modo que era um momento de oferecer às meninas e moças das imediações uma educação religiosa católica. No carnaval, o Oratório abria suas portas durante os três dias, buscando afastar, principalmente, as moças das festividades de rua, considerado pela Igreja uma festa deturpadora dos valores morais.

As modalidades de ensino formal constituíam-se no Internato e Externato. Para o externato funcionou, no período de 1928 a 1936, uma Escola Pública isolada, mantida pelo Estado. Nela, matriculavam-se em média 50 alunas por ano. Quando a escola isolada fechou, a diretora providenciou a construção de um espaço para atender as meninas das proximidades - 0 Externato do Oratório Festivo "São João Bosco" - de cunho particular que chegou a atender quase 100 alunas por ano, a partir de 1938.

No ensino formal, a instituição adotava - conforme os Relatórios enviados à Diretoria de Instrução Pública do Estado e assinalados nos Anais da instituição - um conjunto de disciplinas deliberado no Regulamento da Instrução Pública para o ensino primário. A época baseava-se pelo Decreto $n^{\circ} 867$ de 11 de março de 1924, na gestão de Maurício Graccho Cardoso, a instrução primária estava "dividida em elementar e superior de três anos cada uma” (ESTADO DE SERGIPE, Regulamento da Instrução Pública, 1924, p. 6). Desse modo, a instituição oferecia a suas alunas, nos primeiros tempos, somente o primário elementar. Nas entrevistas, as alunas lembraram-se das aulas de Português (Cartilha), Matemática (Tabuada), aulas de 
Postura e Trabalhos Manuais. Porém, nos Relatórios e Anais da instituição, registrou-se que se oferecia o ensino primário especificado pela Instrução Pública do Estado, o qual segue:

Leitura, Escripta e calligraphia, Arithmetica, comprehendidas as quatro operações fundamentaes e o systema métrico decimal. Chorographia do Brasil e de Sergipe (generalidades), Noções de Historia do Brasil e de Sergipe. Rudimentos de moral e instrucção cívica, urbanidade e hygiene. Molestias mais comuns em Sergipe e meio de prevenil-as. Por meio de licções de coisas: noções simples acerca de estructura e funcções do corpo humano; animaes, plantas e objectos de immediata utilidade; phenomenos atmosphericos.

Elementos de trabalho manual. Cartonagem. Prendas de agulha e outros misteres domésticos, inclusive lavado e engomado, cultivo de hortas e jardins, para meninas, Gymnastica, Formações, marchas. (ESTADO DE SERGIPE, Regulamento da Instrução Pública, 1924, p. 32).

O Código de Menores Melo Matos prescrevia, em seu art. 191, que as instituições de abrigo oferecessem aos menores "exercicios de leitura, escripta ou contas, lições de cousas e desenho, trabalhos manuaes, gynnastica e jogos desportivos". No art. 202, descreviam-se algumas atividades de trabalhos manuais para as meninas, que consistia em "costura e trabalhos de agulha, Lavagem de roupa, Engomagem, Cozinha, Manufactura de chapéos dactylographia, Jardinagem, horticultura, pomicultura e criação de aves" (Código de Menores, 1927, p. 31-32). Assim, a grade curricular determinada pelo Código de Menores exigia o mínimo estabelecido pela Diretoria da Instrução Pública brasileira.

No Oratório Festivo Dom Bosco, além das disciplinas obrigatórias prescrita pelo Regulamento de Instrução, oferecia-se como complemento ao programa, aulas de: Religião, Música, Teoria Musical, Coral e Piano. Oferecia ainda, aulas de Noções de Civilidade e Postura, Canto Orfeônico, Ginástica, Teatro (Relatório, 1933-1934). Para as aulas de Trabalhos Manuais propostas pelo Regulamento, a instituição ofertava: Corte e Costura, Bordado, Flores Artificiais, Tapeçaria, Pintura e Desenho. Prendas Domésticas: Cozinhar, Lavado e Engomado, Limpeza da Casa (Anais, 1925-1952).

Como já mencionamos, no Sistema Preventivo de Dom Bosco, era imprescindível advertir ao aluno das normas contidas no Regulamento, para que ele soubesse de seus deveres e o grau das punições quando cometesse alguma indisciplina. No entanto, "avisar" sobre as regras não era o suficiente para manter a ordem e a disciplina. 0 controle do espaço temporal era primordial para o sucesso da padronização das ações e das atitudes do aluno, pois, o controle do tempo por meio das atividades físicas, escolares e religiosas, além de prevenir contra a ociosidade, era uma forma de interiorizar as divisões do espaço temporal, no qual deveria habituar-se a preenchê-lo organizadamente para saber diferenciar o tempo das atividades laborais e os momentos de descanso.

Assim sendo, as atividades distribuídas na instituição ocupavam as alunas em tempo integral. 0 dia era organizado com diversos afazeres no sentido de impedi-las a cometer faltas. Para Santos (2000), a organização do espaço escolar e da rotina diária do (a) aluno (a) eram estratégias de controle e de prevenção, posto que a preocupação consistia em não deixar os alunos ociosos. Assinalou ainda que "por meio do controle do tempo e do espaço legitimava-se e transmitia-se aos alunos um conjunto de valores culturais e sociais que definiam e instituíam um determinado discurso pedagógico, uma cultura educativa e certas regras de conduta" (SANTOS, 2000, p. 164).

A forma de educação de internato iniciou-se no Oratório Festivo Dom Bosco em novembro de 1920, com o acolhimento de duas irmãs pobres que perderam a mãe. Uma com doze anos e outra com oito anos de idade. Com o decorrer dos anos a instituição expandiu o atendimento. Atendendo meninas até mesmo do exterior (Portugal). 
O controle do tempo e do espaço proporcionado no Oratório Festivo Dom Bosco, principalmente, aquele direcionado às alunas em regime de internato tornou-se condição adequada para aquisição ou formação de um habitus, que foi construído a partir das relações entre todos os seus agentes e por intermédio da aplicação de ações pedagógicas que procuraram conformar nas educandas uma linguagem específica para "percepção e apreciação" do mundo social ${ }^{5}$, bem como, a formação de "esquemas de classificação" (BOURDIEU, 2004, p. 158), ou "habilidades sociais" (ELIAS, 1994, p. 48), suficientes para se comportar devidamente em alguns ambientes sociais, a exemplo da Igreja, da rua ou de casa. Todavia, tais habilidades tornar-se-iam mutáveis conforme o grau de experiências que as alunas fossem submetidas dentro da instituição ou quando fora dela.

Os agentes do processo educativo distribuíam a rotina diária das alunas de forma que "o tempo escolar [estivesse] vinculado ao tempo religioso [] e também um tempo de trabalho" (NASCIMENTO, 2007, p. 176-177), visando incorporar "estruturas estruturadas estruturantes" (BOURDIEU, 2009), que definiam um costume e um ritmo, por que "tudo era dividido por hora e dava tempo para tudo", conforme relatou a ex-interna Ferreira (2008).

Rodrigues (2010), ex-interna que entrou na instituição em 1948, ressaltou que o dia começava cedo e era organizado. "A gente acordava cedo para ir à missa. Toda vida teve missa, tinha um padre que ia celebrar a missa no Oratório, padre Adriano. Era costume, mãezinha botou aquele ritmo. Ela era muito religiosa, tinha vontade de ser freira, mas não foi." (RODRIGUES, 2010).

Em suas declarações Rodrigues (2010), descreveu a distribuição do tempo de forma minuciosa:

5. O mundo social para Bourdieu "pode ser dito e construído de diferentes maneiras, de acordo com diferentes princípios de visão e divisão - por exemplo, as divisões econômicas e as divisões étnicas, religiosas." BOURDIEU, 2004, p. 159
Todo dia tinha missa, a gente acordava cedo às 5:30 horas, tomava banho, se vestia. Às 6:00 horas [...] tinha que estar na Igreja. A primeira coisa do dia era a missa. Depois da missa a gente saía todas em fila direitinho ia pro refeitório tomar café. Depois do Café era que a gente voltava para trocar de roupa [vestir o fardamento diário] e começar as aulas de 8:00 ao meio dia [...]. Depois das 13:00 horas a gente ia fazer as obrigações da casa [...]. Quando era 14:00 horas em ponto tinha aulas de trabalhos manuais com dona Aurinha. No intervalo tinha lanche às 3:00 da tarde, lanchava e voltava logo. E assim passava a hora até às 4:00 da tarde, quando a gente era dispensada ia tomar banho. [...] Depois do banho às 6:00 da tarde, o sino tocava. Pelo sino a gente já sabia [...] que era hora do Angelus. [...] Todas as alunas juntas, acompanhavam. Depois do canto a Nossa Senhora, dali mesmo fazia a fila e ia para o refeitório tomar café. [...]. Depois limpávamos o refeitório e a gente podia brincar no pátio até à hora de se recolher às 8:30 horas da noite. Mas antes de subir para o dormitório a gente fazia um lanche. [...] Já no quarto antes de deitar a gente rezava ao pé da imagem de N. S. Auxiliadora que ficava no centro do dormitório. Depois tinha o Boa Noite que mãezinha dizia pra gente, alguns avisos de coisas que a gente não devia fazer, ter fé em Dom Bosco, e outros conselhos. [...] Uma auxiliar ficava vigiando a gente pra ficar em silêncio até dormir. (RODRIGUES, 2010).

Constatou-se através desse depoimento e de outros similares, que o cotidiano das alunas estava dividido em vários momentos, vivido em lugares determinados e específicos. O dia era um período de aprendizado, dividido em tempos de estudar, o tempo da higiene e da alimentação, aquele dedicado aos ofícios religiosos, o tempo do trabalho (afazeres domésticos) e o tempo da recreação e descaso. É a partir desses momentos específicos que se apresenta a rotina diária das internas.

\section{TEMPO DE ESTUDAR E APRENDER}

A carga horária do ensino primário das alunas do internato do Oratório Festivo Dom Bosco distribuía-se em dois momentos: de oito às doze horas, para as meninas pequenas e médias, cursando o primeiro e segundo anos; e das treze às dezessete horas para as meninas maiores, que cursavam o terceiro e quarto anos. 
As informações sobre as disciplinas oferecidas foram fornecidas por meio de depoimentos das ex-internas e através do Relatório da instituição datado de 1936. O conjunto de disciplinas estava composto por: Caligrafia, Noções de História e Geografia, Ciências, Português, Noções de Civilidade e Postura, Matemática, Serviços Domésticos (Obrigações), Trabalhos Manuais (Costura e Bordado), Música e Piano, Ensino Religioso, Ginástica, Canto Orfeônico e Catecismo.

No período letivo, desenvolviam-se diversas práticas festivas e religiosas propostas no calendário salesiano, que se articulava com as práticas dos estudos regulares por intermédio das dramatizações, declamações, jogos e brincadeiras. Essas atividades extras contribuíram para transmitir o ensino religioso, bem como, os valores morais e código de comportamentos sociais que tinha disciplina específica - as aulas de Postura e Noções de Civilidade.

As aulas de Postura e Noções de Civilidade foram muito importantes no quadro curricular, porque visavam ensinar as boas maneiras às alunas para apresentarem-se corretamente em público. Objetivavam ainda trabalhar a "natureza" destas, através do "mecanismo do controle das emoções" (sensibilidades e sensações), pois, as moças tinham que aprender a "policiar o próprio comportamento" (ELIAS, 1994, p. 93). Para isso, no decorrer da disciplina impunham-lhes um conjunto de atividades (dramas, canções, hinos religiosos, orações, jogos, entre outros), no sentido de auxiliar na "formação de sensibilidades recatadas, civilizadas, consideradas indispensáveis como signos de refinamento" (CUNHA, 2006, p. 353).

\section{TEMPO DESIGNADO AOS TRABALHOS MANUAIS E SERVIÇOS DOMÉSTICOS}

Para Dom Bosco, o lema da vida era educar para o trabalho e religião. Seu ponto de vista sobre o trabalho era de que: "um trabalho bem feito e bem progra- mado jamais será prejudicial à saúde de quem quer seja". Alertou ainda que o "trabalho sempre será portador de uma dignidade especial para a pessoa, traz respeito e admiração perante a sociedade e será um meio eficaz de evitar o mal moral e a ofensa a Deus" (CASTRO, 2003, p. 23).

O Trabalho Manual foi uma disciplina evidenciada no ensino de meninos e meninas com o sentido de: ocupar o tempo dos alunos, transmitir uma linguagem ou expressar um sentimento. Contudo, o importante em adotar a disciplina nos currículos foi pela colaboração no processo de aprendizagem na educação do corpo e o controle da mente.

Conforme os Regulamentos de Ensino Primário da época estudada, as atividades manuais para meninas divergiam dos meninos. Para elas, referia-se comumente a Trabalhos de Agulha e Prendas Domésticas. No Oratório Festivo Dom Bosco, para as atividades dos trabalhos de agulha, foi oferecido com frequência bordado e corte e costura. O tricô, o crochê e a tapeçaria também foram contemplados, mas pelos depoimentos das ex-alunas e o que se encontrou nos Anais (1925-1952), se deu com menor ênfase.

Os trabalhos de agulha realizavam-se em local específico - no atelier. Nas aulas de Costura, aprendia-se a confeccionar vestidos, camisas, roupinhas de bebê, e "fazer bainhas de toda qualidade" (RAMOS, 2010): "pé de galinha para calças, saias e vestidos" e bainha aberta, que "servia para acabamento de bordado feitos em toalhas, colchas, guardanapos, lenços", (FERREIRA, 2008); enfim, eram pontos de acabamento comum que serviam para diversos trabalhos de costura e bordado.

Conforme Ferreira (2008), o corte e a costura aprendiam primeiro no papel para "depois ir para os tecidos". Quando aprendiam, confeccionavam seus vestidos "na mão, com ponto atrás" (FERREIRA, 2008). 
Nos documentos preservados na instituição encontram-se alguns cadernos de receitas. No caderno de bordado havia diversos pontos: o ajour de agulha, paris, romano, romeno, ponto cheio, cascado, cetim, ponto cruz, cadeia, preguiçoso, carreira, grão, ponto haste, mosaico, caseado, nós franceses, rosa comum, rendendê, perfilado.

\section{TEMPO RESERVADO AOS RITUAIS RELIGIOSOS}

No decorrer da pesquisa verificou-se que as atividades religiosas das alunas eram intensas. As depoentes de todas as categorias (internas, externas e oratorianas), ao falarem sobre o cotidiano, foram enfáticas ao dizer que a missa era a primeira atividade do dia, antes mesmo da alimentação matinal. Conforme ensinamento de Dom Bosco, "a oração, eis a primeira coisa; e com a oração, o trabalho" (CASTRO, 2003, p. 22). Assim recomendava-se primeiro alimentar 0 espírito para depois cumprir as obrigações materiais.

Depois da missa as demais atividades aconteciam em variados espaços e momentos. No refeitório, antes mesmo de sentarem nos lugares determinados ouviam a alocução de Genésia Fontes em agradecimento ao santo alimento, a Nosso Senhor e a Dom Bosco, depois rezavam a Ave-Maria e Pai Nosso. Na sala de aula, antes de começar as atividades escolares, em pé, a professora rezava juntamente com as alunas as orações básicas. 0 mesmo acontecia na sala de costura ao iniciar as aulas de trabalhos manuais.

No entanto, outras práticas religiosas ocorreram na instituição entendidas neste trabalho como formas ${ }^{6}$ de linguagem ${ }^{7}$. 0 mês mariano e as flores, o Santo Natal, Árvore de Natal, presépio e o papai-noel, os festejos a

6. Conforme Bourdieu, "dar forma" - significa "dar a uma ação ou a um discurso a forma que é reconhecida como conveniente, legítima, aprovada, [...] uma forma tal que pode ser produzida publicamente diante de todos, uma vontade ou uma prática que apresentada de outro modo, seria inaceitável [...]. BOURDIEU, 2004, p. 106.

7.Chartier aludiu que "a construção dos interesses pelas linguagens disponíveis" (ou formas de expressão) "em um determinado tempo sempre está limitada pelos recursos desiguais (materiais, linguísticos ou conceituais) de que dispõem os indivíduos" e somente terão sentido e eficácia, conforme a apropriação de seus atores, pois, eles inventam e reinventam as práticas de representação. CHARTIER, 2009, p. 48.
Dom Bosco e o beijamento de sua relíquia, as imagens de santos, santinhos, os milagres atribuídos a Dom Bosco, e os retiros, auxiliaram e muito na transmissão dos ensinamentos religiosos proporcionados pela instituição, visando à formação de um habitus religioso nas alunas que deveriam incidir nos gestos, no corpo e nos pensamentos.

Os recursos utilizados na transmissão foram variados, tais como: máquina cinematográfica e vitrola, o piano e o harmônio, do mesmo modo, as variadas atividades culturais desenvolvidas na instituição. A dramatização e a música foram os preferidos porque atraíam alunas e a comunidade.

Os retiros e o mês mariano no Oratório Festivo Dom Bosco aconteciam anualmente num período de três dias, geralmente, quatro práticas diárias. Era uma prática regulada e obrigatória para as alunas, principalmente, internas, bem como para as externas (em que poderiam participar pessoas da comunidade), "às superioras, catequistas, e às companhias”. (Anais, 1925-1952).

A Congregação Salesiana foi solidária com o movimento de consagração a Maria, através de sua santa padroeira Nossa Senhora Auxiliadora e festejava com pompa. Desde a origem do Oratório Festivo Dom Bosco seus membros participaram das devoções a N. S. Auxiliadora organizada pelos Salesianos, que constava de novenas, Missa cantada, procissão, ornamentação do altar, adornamento da imagem de N. S. Auxiliadora e comunhões.

Um dos rituais, flores espirituais à Maria, consistia em praticar uma virtude e rezar uma jaculatória em honra de Nossa Senhora diariamente no decorrer do mês mariano, para isso, a aluna "colhia" um pedaço de papel onde estava escrito uma virtude a ser cumprida durante aquele dia. As "flores” à Maria estavam representadas da seguinte forma: "Sê suave com todos, especialmente com quem te contraria"; "A cada pensamento de vaidade repete: De que serve isto para o paraíso?"; "Guarda o ouvido de toda palavra mal reta. Segue hoje as boas inspirações", entre outras encontradas na documentação da instituição. 
Assim, concluiu-se que a religiosidade estava presente em momentos diversos da instituição com a finalidade de disseminar a fé católica nas alunas e entre seus familiares. Os rituais referidos e desenvolvidos na instituição pelas educandas, tais como "queimar círios (grande vela de cera) ao pé da santa virgem", "ofertar flores a Maria" e os exercícios marianos regulares e repetitivos, com tempos determinados visavam uma incorporação automática desses sacramentos, semelhantemente ocorrendo com outras festas de caráter religioso promovidas pela instituição. Desse modo, constatou-se que os as práticas educativas, festivas e religiosas desenvolvidas na instituição colaboraram para as formas de apropriação daquelas crianças e que se reproduziram para além do ambiente escolar. Verificou-se que a educação oferecida proporcionou as meninas uma formação civilizada e consciente de seu estado no mundo e sua posição social. Vale lembrar que apesar das alunas serem incentivadas em escolher como profissão o trabalho doméstico ou o magistério, isso não impediu de algumas galgarem profissões adversas das estabelecidas ou seguirem caminhos diferentes dos ensinados na instituição.

\section{REFERÊNCIAS}

BISPO, Alessandra Barbosa. A educação da infância pobre em Sergipe: A Cidade de Menores "Getúlio Vargas” (1942-1974). São Cristóvão: UFS/NPGED. 2006. Dissertação (Mestrado em Educação).

BONIFÁCIO, Nadja Santos. Acolher, evangelizar e educar: a contribuição do Oratório Festivo São João Bosco para educação feminina de Aracaju (19111950). São Cristóvão: UFS/NPGED. 2011. Dissertação (Mestrado em Educação).

BOURDIEU, Pierre. Coisas Ditas. São Paulo: Brasiliense, 2004.
CHARTIER, Roger. A história ou a leitura do tempo. Belo Horizonte: Autêntica Editora, 2009.

CHARTIER, Roger. À beira da falésia: a história entre incertezas e inquietudes. Porto Alegre: Ed. Universidade/UFRGS, 2002.

CHARTIER, Roger. A aventura do livro: do navegador ao leitor. São Paulo: Editora UNESP/Imprensa Oficial do Estado de São Paulo, 1999.

CONCEIÇÃO, Joaquim Tavares da. A Pedagogia de Internar: uma abordagem das práticas culturais do internato da escola Agrotécnica Federal de São Cristóvão/SE (1934-1967). São Cristóvão/SE: UFS/NPGED, 2007. Dissertação (Mestrado em Educação).

COSTA, Rosemeire Marcedo. Fé, Civilidade e Ilustração: as Memórias de Ex-Alunas do Colégio Nossa Senhora de Lourdes (1903-1973). São Cristóvão-SE: UFS/ NPGED, 2003. Dissertação (Mestrado em Educação).

CUNHA, Maria Teresa Santos. Tenha Modos! Manuais de Civilidade e Etiqueta na Escola Normal (Anos 1920-1960). In: Anais do VI Congresso Luso-Brasileiro de História da Educação: Percursos e Desafios da Pesquisa e do Ensino de História da Educação. COLUBHE06. Uberlândia/MG: UFU, 2006, p. 350-361.

ELIAS, Norbert. 0 processo civilizador. Rio de Janeiro: Jorge Zahar Editora, 1994.

HILSDORF, Maria Lúcia Spedo. Tão longe, tão perto - As meninas do Seminário. In: STEPHANOU, Maria; BASTOS, Maria Helena Camara. Histórias e memórias da educação no Brasil: vol. II - século XIX. Petrópolis/RJ: Vozes, 2005, p. 52-67.

KUHLMANN Jr., Moysés. A circulação das ideias sobre a educação das crianças; Brasil início do século XX. In: KUHLMANN Jr., Moysés; FREITAS, Marcos Cesar de. Os intelectuais na história da infância. São Paulo: Cortez, 2002, p. 459-503. 
LOURO, Guaraci Lopes. Gênero, sexualidade e educação: uma perspectiva pós-estruturalista. Petrópolis, RJ: Vozes, 1997.

MARCÍlIO, Maria Luiza. História Social da Criança Abandonada. São Paulo: Editora Hucitec, 2006

MELO, Valéria Alves. As Filhas da Imaculada Conceição: um Estudo sobre Educação Católica (19151970). São Cristóvão-SE: UFS/NPGED, 2007. Dissertação (Mestrado em Educação).

NASCIMENTO, Ester Fraga Vilas-Boas Carvalho do. Educar, curar, salvar: uma ilha de civilização no Brasil tropical. Maceió: EDUFAL, 2007.

NASCIMENTO, Jorge Carvalho do. Memórias do aprendizado: 80 anos de ensino agrícola em Sergipe. Maceió: Edições Catavento, 2004.

NERY, Marcos Arlindo Amorim Melo. A Regeneração da Infância pobre sergipana no início do século XX: o patronato agrícola de Sergipe e suas práticas educativas. São Cristóvão: UFS/NPGED, 2006. Dissertação (Mestrado em Educação).

PATRÍCIO, Solange. Educando para o trabalho: a implantação da Escola de Aprendizes Artífices de Sergipe (1910-1930). São Cristóvão: NPGED/UFS, 2003. Dissertação (Mestrado em Educação).

RAGO, Margareth Luiza. Do cabaré ao Lar: a utopia da cidade disciplina: Brasil (1890-1930). Rio de Janeiro: Paz e Terra, 1990.

ROCHA, Heloísa Helena Pimenta. A higienização dos costumes: educação escolar e saúde no projeto do Instituto de Hygiene de São Paulo (1918-1925). Campinas, SP: Mercado das Letras; São Paulo: Fapesp, 2003.

RIZZINI, Irma. Meninos Desvalidos e menores transviados: a trajetória da assistência pública até a Era
Vargas. In: RIZZINI, Irene; PILLOTTI, Francisco. A Arte de Governar crianças: a história das políticas sociais, da legislação e da assistência à infância no Brasil. São Paulo: Cortez, 2009, p. 225-286.

RIZZINI, Irene. 0 século Perdido: raízes históricas das políticas públicas para a infância no Brasil. São Paulo: Cortez, 2008.

RODRIGUES, Simone Paixão. Por uma educação católica: um estudo sobre a disciplina religião no Ginásio Santa Terezinha (1947-1968). São Cristóvão: NPGED/UFS, 2008. Dissertação (Mestrado em Educação).

SANTOS, Manoel Isaú Souza Ponciano dos. Luz e Sombras: internatos no Brasil. São Paulo: Ed. Salesiana Dom Bosco, 2000, p. 183.

SCARAMUSSA, Tarcísio. 0 Sistema Preventivo de Dom Bosco: um estilo de educação. São Paulo: Editorial Dom Bosco, 1977. (Coleção Pedagogia Viva).

\section{FONTES ORAIS}

FERREIRA, Reuza Maria Lopes. Entrevista concedida a Nadja Santos Bonifácio a 26 de outubro de 2008 e a 13 de agosto de 2010. (interna). Aracaju/SE.

RAMOS Isabel Maria. Entrevista concedida a Nadja Santos Bonifácio a 21 de agosto de 2010. (oratoriana). Aracaju/SE.

RODRIGUES, Maria Madalena da Conceição. Entrevista concedida a Nadja Santos Bonifácio a 11 de janeiro de 2010 e a 12 de julho de 2010. (interna). Aracaju/SE.

\section{DOCUMENTOS INSTITUCIONAIS}

Anais do Oratório Festivo São João Bosco, 1925-1936. ESTADO DE SERGIPE. Regulamento da Instrução Pública. Aracaju, 1924. 
Oratório Festivo São João Bosco. Relatório do Oratório Festivo Dom Bosco, 1933.
Oratório Festivo São João Bosco. Relatório do Oratório Festivo Dom Bosco, 1934. 